http://dx.doi.org/10.35381/racji.v6i1.1424

\title{
La impugnación del reconocimiento de paternidad y el principio del interés superior del niño
}

Challenging the recognition of paternity and the principle of the best interests of the child

\author{
Juan Carlos Arandia-Zambrano \\ uq.juanarandia@uniandes.edu.ec \\ Universidad Regional Autónoma de los Andes, Quevedo \\ Ecuador \\ https://orcid.org/0000-0001-7301-5447 \\ Luis Antonio Rivera-Velasco \\ uq.luisrivera@uniandes.edu.ec \\ Universidad Regional Autónoma de los Andes, Quevedo \\ Ecuador \\ https://orcid.org/0000-0003-2094-9566 \\ Nancy Cecilia Zapata-Jaramillo \\ dq.nancyczi52@uniandes.edu.ec \\ Universidad Regional Autónoma de los Andes, Quevedo \\ Ecuador \\ https://orcid.org/0000-0002-3767-1137
}

Recepción: 15 de marzo 2021

Revisado: 25 de mayo 2021

Aprobación: 15 de junio 2021

Publicación: 01 de Julio 2021 


\section{Estimado Editor (a):}

El marco constitucional de la República de Ecuador del 2008, en su artículo 44 establece el interés superior del niño, con el objeto de garantizar el desarrollo integral, psicológico y físico de los menores de edad, por lo tanto, sus derechos prevalecerán por encima de cualquier otro derecho. Pero en algunos casos se platean situaciones en las cuales se ve involucrado el menor, por decisiones asumidas por sus padres.

Al respecto, cuando existe la duda de la paternidad y uno de los progenitores objeta, existe una forma de iniciar una acción legal de objeción de reconocimiento de paternidad, será demostrando que el consentimiento fue viciado al haber existido error, fuerza y dolo al momento de reconocer legalmente al niño o niña, ya que la reforma del código civil vigente, tuvo como objeto evitar juicios de impugnación de reconocimiento de paternidad sin fundamentación, incluso han llegado ante la Corte Nacional de Justicia, como órgano máximo de administración de justicia y como última instancia del recurrente.

Por otro lado a pesar de que el acto de reconocimiento de paternidad fueron mediante engaños o mentiras, es decir no hubo consentimiento libre y voluntario, la ley de forma clara y precisa, en el respectivo código civil vigente, señala que la acción podrá ser ejercida únicamente por el hija o hijo, y por quienes tengan interés en ello, mientras que el reconociente podrá iniciar un juicio de nulidad, sin embargo la prueba de ADN carece de validez ante esta causa, por tanto, se dificulta demostrar que el consentimiento vicia de error, fuerza o dolo. Los procesos de impugnación de la paternidad, implican no solo aspectos jurídicos, sino también psicológicos y sociales (Camargo y Ospino Rodríguez,2013, p.8)

Los fundamentos jurídicos que contemplan todo lo relacionado al tema en estudio se pueden descrinar de la siguiente forma:

El organismo Jurídica, concerniente a la impugnación de paternidad y el progreso de forma integral de los menores se contempla en nuestra carta magna, Constitución de la República de Ecuador en el artículo 69, señala: 
Para proteger los derechos de las personas integrantes de la familia: 1 . Se promoverá la maternidad y paternidad responsables; la madre y el padre estarán obligados al cuidado, crianza, educación, alimentación, desarrollo integral y protección de los derechos de sus hijas e hijos, en particular cuando se encuentren separados de ellos por cualquier motivo....

Así mismos, el Código Civil del 2005, desde los artículos 233 al 242 expresan lo relacionado a los hijos concebidos en matrimonio y la presunción de paternidad. En este mismo orden, los artículos 33, 50, 148,150, del Código Orgánico de la Niñez y Adolescencia establecen: "Derecho a la integridad personal. - Los niños, niñas y adolescentes tienen derecho a que se respete su integridad personal, física, psicológica, cultural, afectiva y sexual. No podrán ser sometidos a torturas, tratos crueles y degradantes". Para continuar la Ley del Registro Civil, Identificación y Cedulación (2013) en su artículo 69 plantea: "Repudio e impugnación. El repudio del reconocimiento o la sentencia ejecutoriada que acepte la impugnación de la paternidad o maternidad, se subinscribirán al margen de la respectiva partida de nacimiento". Por lo tanto, esta relación paterno-filial es aquella que surge hacia los hijos biológicos o hacia aquellos que fueron reconocidos mediante un acto libre y voluntario, y bajo este contexto se hace evidente el principio de corresponsabilidad, en donde el padre y la madre tienen la misma obligación y derechos hacia sus hijos. Sin embargo, en algunos casos ocurren hechos en los cuales los hijos no son reconocidos, al respecto Tantaleán Mesta (2017) indica que:

La situación problemática que surge en el presente tema consiste en la forma de cómo el ordenamiento civil regula la acción de impugnación de paternidad matrimonial, la cual se encuentra limitada o condicionada normativamente para realizar una adecuada y libre investigación de la paternidad del hijo reconocido dentro del matrimonio, afectando así un derecho fundamental como lo es el derecho a la identidad del menor. (p.10)

En concordancia con el artículo 184 numeral 2 de la Constitución de la República del Ecuador (2008) establece entre las funciones de la Corte Nacional de Justicia reside en: Desarrollar el sistema de precedentes jurisprudenciales fundamentado en los fallos de triple reiteración. En este sentido, estos precedentes jurisprudenciales permiten que los 
casos presentados sobre un mismo punto de hecho o derecho, obligue a que, en las Cortes respectivas, se dé la misma resolución, es decir, el recurrente tendrá la misma resolución judicial, al existir este precedente jurisprudencial.

Por otro lado, en el Código Civil ecuatoriano (2005), en concordancia de los artículos 247, 248 , faculta a que los hijos que no son concebidos dentro del matrimonio, puedan ser reconocidos como hijos, mediante un acto libre y voluntario, al igual la ley de forma clara manifiesta que es un acto irrevocable, pero al estar viciado la ley facultad a iniciar un proceso legal.

Sin embargo, el artículo 250 ibídem, manifiesta que la acción de impugnación del reconocimiento de paternidad puede ser ejercida por el hijo y por cualquier persona que pruebe interés en ello, cuya acción es mediante procedimiento ordinario, señalando que el reconociente únicamente podrá realizarla mediante vía de nulidad de acto, en donde su medio de prueba consistirá en demostrar que su consentimiento fue viciado, aunque en la generalidad de los casos es difícil de demostrar. En tal sentido, los operadores de justicia, en estos casos las juezas o jueces en los respectivos tribunales o salas en materia de niñez y adolescencia, buscan precautelar los derechos de los niños, niñas y adolescentes, en donde prima el interés superior del niño en toda decisión judicial.

Ahora bien, mediante él estudió doctrinario, jurisprudencial, y al respectivo ordenamiento jurídico ecuatoriano, según su orden jerárquico, se observan ciertas particularidades que presenta el ejercicio de objeción del reconocimiento de la paternidad, entre ellas la diferencia de su procedencia únicamente se establece en el artículo 250 del Código Civil(2005), en virtud que el reconociente no puede alegar desconocimiento de un acto que ha manifestado en su consentimiento y voluntad al momento de realizarlo, considerado ante la ley como un acto irrevocable.

En referencia a la acción legal para impugnar el reconocimiento de paternidad, debido a la carencia de pruebas que determinan la existencia de vicios que violentan el consentimiento por parte del reconociente, ya que la prueba de ADN en estos juicios no constituye prueba suficiente, debido a que el reconociente realizó el acto de manera libre 
y voluntario, pese a que biológicamente no era suyo. Para finalizar se indica que la finalidad del quehacer de impugnación del reconocimiento de paternidad, radica en cuanto a los legitimarios activos buscan dar por terminado el vínculo o filiación existente entre los padres e hijos, ya que el reconociente a sabiendas que biológicamente no es el legítimo padre o madre lo haya reconocido, por lo tanto mediante el estudio analítico, se concluye que el Estado garantiza protección legal a los hijos que fueron concebidos fuera de matrimonio y están reconocidos mediante un acto libre y voluntario.

\section{FINANCIAMIENTO}

No monetario.

\section{AGRADECIMIENTO}

A la Universidad Regional Autónoma de los Andes, Ecuador; por motivar el desarrollo de la Investigación.

\section{REFERENCIAS CONSULTADAS}

Asamblea Nacional Constituyente de la República del Ecuador, (2008). Constitución de la República del Ecuador. [Constitution of the Republic of Ecuador]. Montecristi. Registro Oficial 449 de 20-oct-2008. Recuperado de https://n9.cl/sia

Asamblea Nacional de Ecuador. (2019). Código Civil. [Code of Childhood]. Quito: Registro Oficial Suplemento, 46.

Camargo, E., y Ospino Rodríguez, M. (2013) Principio Del Interés Superior Del Niño, Niña y Adolescente, Analizado en un Proceso de Impugnación de la paternidad en Barrancabermeja-Santander. [Principle of the Best Interests of Children and Adolescents, Analyzed in a Process of Challenge to Paternity in BarrancabermejaSantander]. Tesis de Maestría. Universidad Santo Tomás Facultad de Psicología. Maestría en Psicología Jurídica: Recuperado de: https://n9.cl/kmri6

Código Civil Ecuatoriano (2005). [Code of Childhood]. Oficio No. 0110-CLC-CN-05. Recuperado de https://n9.cl/x6zee 
Congreso Nacional (2003). Código de la Niñez y Adolescencia. [Code of Childhood and Adolescents]. publicado por Ley No. 100. en Registro Oficial 737 de 3 de enero del 2003. Recuperado de: https://n9.cl/dtrec

El Consejo Supremo de Gobierno (2013) Ley de Registro Civil, Identificación y Cedulación. [Civil Registration, Identification and Identification Act]. (Decreto Supremo No. 278). Recuperado de: https://n9.cl/dqg4

Tantaleán Mesta, M. (2017) La Vulneración del derecho a la identidad del menor en los casos de impugnación de paternidad matrimonial. [Violation of the right to the identity of the minor in cases of contestation of marital paternity]. Tesis Para Optar El Título Profesional de Abogada. Universidad de San Miguel de Porres. Lima Perú. Recuperado de: https://n9.cl/cf1rg 